\title{
The Strategic Choice of RMB Internationalization under the Two-way Opening of Finance in the New Era
}

\author{
Degong $\mathrm{Ma}^{1, \mathrm{a}}$,Lei Teng ${ }^{2, \mathrm{~b}}$ \\ ${ }^{1}$ No.24 South Section 1, Yihuan Road, Chengdu, China, 610065 \\ ${ }^{2}$ No.24 Block 1, Xuefu Road, Chengdu, China \\ a degongma@126.com, btenglei@cuit.edu.cn
}

Keywords: the New Era, Two-way Opening, RMB Internationalization.

\begin{abstract}
The two-way opening of finance is the inevitable choice for China to build a high level open pattern in the new era, It is essential to consider the logical evolution process of two-way financial opening for RMB internationalization, and then to clear the strategic functions and objectives RMB internationalization. RMB should participate in global financial governance actively, explore the development direction of the dual drive of securities and reserve assets. At the same time, China should Perfect the prudent and orderly financial market construction, so that to promote the off-shore and on-shore dual markets financial support system to RMB internationalization. in order to promote the internationalization of the RMB China can also strengthen the financial innovation by The Belt and Road construction.
\end{abstract}

\section{新时代金融双向开放下的人民币国际化战略选择}

\section{马德功 ${ }^{1, a}$, 滕䂞 ${ }^{2, b}$}

1 四川大学经济学院, 成都, 四川, 中国

2 四川大学经济学院, 成都, 四川, 中国; 成都信息工程大学商学院, 成都, 四川, 中国

a degongma@126.com, btenglei@cuit.edu.cn

关键字: 新时代 双向开放 人民币国际化 一带一路

摘要：金融双向开放是新时代中国建设高层次开放格局的必然选择，在此背景下人民币国际 化需要考虑金融双向开放的逻辑演进过程，明确人民币国际化的战略职能和目标。人民币应 积极参与全球金融治理，探索由证券和储备资产双驱动的发展方向，完善稳健有序的金融市 场建设，提升离岸和在岸双市场对国际化的金融支撑体系，并利用 “一带一路”建设加强金 融创新，推进人民币国际化进程

\section{1. 引言}

当前中国已经进入开放引领的新时代，并推动形成全面开放的新格局。新时代的核心内 涵意味着中国正逐步走近世界舞台的中央，开放的领域必须更加广泛，力度更加深远，并逐 步为解决全球治理赤字提供中国智慧和中国方案。这其中，中国金融业的双向开放成为必然 选择，并将成为建设现代经济体系和构建全面开放格局的主力担当。在此过程中，人民币国 际化作为中国经济向世界经济提供的国际公共物品，承担着应对全球周期经济危机和贸易波 动的中国治理责任。如何在新时代金融双向开放的背景下应对国际国内的各种挑战和障碍, 探索人民币国际化的战略路径，为中国企业和居民的国际经济活动保驾护航，推动中国金融 
市场加快融入世界金融体系, 进而为目前的国际货币体系提供来自新兴市场的多样化选择提 供中国方案, 是极为值得深入思考和探究的问题。

\section{2. 新时代背景下我国金融双向开放的逻辑必然}

\section{1 我国金融双向开放的内涵及其逻辑演进}

我国金融开放过程是一个谨慎稳妥推进的过程，其根本原则在于服务我国企业对外贸易 投资和调节外部失衡的同时，防范金融风险，维护国家金融主权。而金融双向开放则意味着 人民币利率和汇率形成机制的完全市场化过程，人民币资本项目可兑换以及国外金融机构和 国际资本自由进入国内从事各类金融投资活动等。这在相当程度上会破坏我国金融体系的稳 定性，并在现有监管制度下产生金融市场失灵，带来风险隐患。为此，有必要厘清我国金融 双向开放的逻辑和演进机理，从而从容推进这一开放进程。

服务于企业的对外贸易和投资需求是我国不断推进人民币汇率改革和稳步开放资本项目 流动的出发点。过去的经验表明我国遵循的贸易投资优先证券投资、长期资本优先短期资本、 资本流入优先资本流出的管理思路在较长时间内体现了其服务企业对外活动防范金融风险的 原则。当前我国经济社会进入新时代, 从企业的国际活动来看, 我国企业开始通过资本和技 术的全球化布局，积极主动参与全球产业链重构过程，巨量的对外投资资金需要更高层次的 金融开放格局与之相适应，这对资本的配置方式和我国金融开放格局提出了新的要求。同时， 我国由外汇储备为主向市场主体为主转变的对外资产持有主体的结构性变化, 也对外汇资产 的多元化配置渠道提出了新的要求，因此，从我国经济发展的结构进程来看，新时代的金融 双向开放逻辑与演进, 是始终适应经济结构的变化和特点, 从而服务实体经济发展和国家总 体战略。

\section{2 金融双向开放：新时代高层次全面开放的必然选择}

作为全球第二大经济体，中国对世界经济增长的贡献率超过美国、日本和欧盟之和，达 到 30\%, 成为名副其实的世界经济动力引擎和稳定之针。但与此同时，我国金融业在全球金 融领域里的话语权与当前经济地位和体量不相匹配，在发挥引领经济发展方面所起的作用仍 大有空间，这与我国金融业的对外开放程度不够有很大关系。新时代背景下，适应我国当前 经济结构转型, 主动参与和积极推动经济全球化进程, 构建对外高层次全面开放格局, 金融 业双向开放是必然选择。只有融入世界金融话语体系并掌握一定的话语权，主动参与全球金 融治理和资源配置过程, 才能更好地发挥金融对经济的引领作用, 推动我国经济从高速增长 阶段向高质量增长转变，而这一过程只能通过金融对外双向开放道路实现。

金融双向开放一方面包括我国金融机构走出去参与全球金融竞争和我国为世界提供金融 治理的全球公共物品, 另一方面包括对国际金融机构准入松闸, 允许其充分参与国内金融市 场活动，同时顺应国际金融市场规则，融入国际金融市场体系。前者伴随着我国企业在 “一 带一路” 等国家战略过程中走出国门为此类企业提供金融服务, 并逐渐提高全球服务能力, 后者则意味着国际金融企业逐步公平参与国内金融市场, 为国内金融机构带来风险管理、质 量提升等方面的先进经验。同时，两者均在一定程度上打破国际国内金融市场的各种壁垒和 机制障碍, 为融通我国境内外资本提供便利, 进而促进我国金融市场融入国际金融体系, 并 提供金融治理和创新的中国智慧。而不管是 “走出去” 还是 “引进来”，都是在更高层次上全 面和国际金融市场接轨，是新时代高层次全面开放在金融开放领域的必然选择。 


\section{3. 人民币国际化与新时代战略}

\section{1 人民币国际化的背景与缘由}

虽然上世纪 90 年代就有人提出过人民币国际化的概念和构想, 但真正意义上的人民币国 际化开端却是 2008 年金融危机过后。肇始于 2007 年的美国次贷危机以美元为载体将危机曼 延至全球主要经济体, 加剧了各国对当前美元霸权地位的担忧, 迫切需要改革当前的国际货 币体系。另一方面, 随着中国经济特别是贸易总额的持续增长, 中国越来越在国际经济增长 和稳定中发挥着重要作用, 中国逐渐壮大的国际经济参与主体和其他国家的相关当事方, 也 越来越期盼人民币在国际经济活动中扮演更重要的角色。因此，人民币的国际化过程既有其 特定的时代背景, 也具有必然的内生动力。

布雷顿森林体系解体三十余年来，美元在全球货币体系中仍然始终扮演着核心角色，美 国持续凭借美元的国际硬通货地位不断通过货币超发、美元贬值等手段篗取其他国家经济果 实, 并将本国金融经济风险传导和转移至世界各国。2008 年的金融危机使人们再次深刻认识 到美元垄断对各国和世界经济带来的社会福利损失, 并积极寻求从一元垄断向寡头垄断的货 币体系新选择。经过改革开放特别是加入 WTO 之后的快速发展，中国的经济总量、贸易总额、 外汇储备在 2010 年均已稳居至世界前两位。随着对外经济活动的加深, 我国经济主体越来越 面临国际汇率风险的冲击, 人民币国际化程度不足也日益成为制约我国改革开放和经济进一 步发展的因素。在我国对公平的国际货币秩序的需求越来越强烈的同时，各国对人民币承担 国际经济交流公共物品的需求也越来越强烈, 而人民币也越来越有能力承担起作为贸易结算、 国际储备和投资工具的责任。在此背景下，人民币开启了其漫长又艰辛的国际化进程。

\section{2 人民币国际化的进展}

人民币国际化的过程，实际上是人民币逐渐承担国际公共物品并发挥作用的过程。经过 十年的发展，人民币在国际市场上已经具备了基本的结算、投资和储备功能，特别是 2016 年 人民币加入 SDR 特别提款权篮子，标志着人民币国际化取得突破进展。人民币作为国际公共 物品，在跨境收付业务、承担储备资产职能、人民币国际债券发行、境外居民持有境内人民 币金融资产、人民币外汇交易和境外现钞流通、双边本币互换、跨境使用基础设施建设等方 面均取得了长足发展。表 1 为人民币国际使用情况表。

表 1：人民币国际使用情况（单位：亿元人民币）

\begin{tabular}{|c|c|c|c|c|c|c|c|}
\hline & $\begin{array}{l}\text { 经常项目人 } \\
\text { 民币收付额 }\end{array}$ & $\begin{array}{l}\text { 跨境直接投资 } \\
\text { 人民币收付额 }\end{array}$ & $\begin{array}{l}\text { 境外官方人 } \\
\text { 民币储备额 }\end{array}$ & $\begin{array}{c}\text { 人民币国 } \\
\text { 际债券余 } \\
\text { 额 }\end{array}$ & $\begin{array}{c}\text { 境外人民 } \\
\text { 币金融资 } \\
\text { 产 }\end{array}$ & $\begin{array}{l}\text { 境内人民币 } \\
\text { 外汇市场日 } \\
\text { 均交易额 }\end{array}$ & $\begin{array}{c}\text { 人民币跨境 } \\
\text { 现钞调运金 } \\
\text { 额 }\end{array}$ \\
\hline 2011 & 15889 & 1273 & & & & & 255 \\
\hline 2012 & 28797 & 2904 & & & & & 290 \\
\hline 2013 & 46368 & 5438 & & & 28797 & & 420 \\
\hline 2014 & 65510 & 11850 & 6667 & 6346 & 44183 & 550 & 516 \\
\hline 2015 & 72344 & 23233 & 8647 & 5996 & 37400 & 728 & 597 \\
\hline 2016 & 52275 & 24606 & 5856 & 6987 & 30337 & 832 & 638 \\
\hline
\end{tabular}

数据来源: 中国人民银行, 人民币国际化报告 $2015,2016,2017$ *单位为亿美元

与此同时, 适应新时代改革、发展和开放的要求, 我国金融市场不断扩大开放，与人民 币国际化相关的改革持续进行。按照 “服务实体, 循序渐进, 统筹兼顾, 风险可控” 的原则, 人民币资本项目可兄换正在稳步推进，全口径跨境融资宏观审慎管理试点已于 2016 年 4 月扩 大至全国范围，从而大幅度提高了跨境投资和交易管理的便利程度。目前人民币在 7 大类共 40 项资本项目交易中，已实现可兄换、基本可兄换、部分可兄换的项目共计 37 项，占全部 交易项目的 $92.5 \%$ 。沪港通、深港通、债券通机制的不断优化和扩容，酝酿中的沪伦通等均 是人民币面向当前新时代发展在资本项目下做出的改革安排。通过金融市场基本利率体系的 
持续培育, 市场利率定价自律机制的不断健全, 金融产品创新的有序推进和央行利率调控体 系的进一步完善，人民币利率市场化改革基本完成，在政府推动人民币国际化进程的同时， 为其准备了充分的市场条件。2015 年新汇改实施以来，人民币汇率中间价形成机制不断完善。 2017 年，在中间价报价模型中增加逆周期因子，适度对冲市场情绪的顺周期波动，使中间价 报价更充分地反映我国经济运行等基本面因素，更真实地体现外汇供求和一篮子货币汇率变 化。这一机制有效抑制了外汇市场上的羊群效应，增强了我国宏观经济等基本面因素在人民 币汇率形成中的作用，保持了人民币汇率在合理均衡水平上的基本稳定，从而也保证了人民 币国际化进程的平稳推进。

\section{3 新时代战略下人民币国际化的问题}

尽管人民币国际化已经取得了相当程度的进展，但人民币成为真正的国际货币还有相当 长的道路要走。进入新时代的中国, 需要通过人民币国际化来提升国际影响力和竞争力, 增 加在地区发展、世界经济乃至地缘政治上的国际地位。显然, 在新时代人民币国际化承担了 中国大国复兴的历史责任。但当前人民币国际化进程由于人民币在资本项目下尚不能完全兑 换, 汇率形成机制仍不够市场化, 国内金融市场体系不够完善等问题, 形成了一些仍待解决 的问题和发展方向。

人民币国际证券资产和储备资产远不足以支撑起国际化目标。推动人民币国际化，参与 全球金融治理，一方面需要全球主权国家有信心将人民币纳入其外汇储备资产，在多元化其 储备货币的同时，提升人民币全球货币治理的功能发挥。另一方面，市场主体有意愿通过理 性评估人民币资产的成本、收益和风险状况，大规模持有人民币资产或负债，从而增强人民 币资产的国际市场规模和流动水平，为包括中国居民主体在内的世界经济和金融市场参与者 提供支付结算、投资套利、风险对冲等不同目的的工具选择。但由于资本流动管制的存在， 以及对人民币国际债券发行等问题的认识不足等，当前人民币证券资产总额与人民币作为真 正国际货币应承担的市场责任相比远远不够。

在岸市场与离岸市场割裂。由于历史原因和风险防范的需要，境内金融市场的探索和发 展, 远不像商品市场一样开放, 包括交易规则、价格形成、参与者画像、风险提示在内的机 制体制以及包括市场流动性、弹性、收益曲线等在内的市场特征和国际市场仍有较大差异， 不同的话语体系导致国际投资者难以适应人民币在岸市场的环境, 从而只能在离岸市场试图 分享中国资本市场的国际红利。但离岸市场与在岸市场的市场规模远不是一个量级, 从而导 致人民币作为国际投融资工具的功能难以发挥。这种人民币对国际市场的供给约束也必然影 响到其他国家将人民币作为储备资产的信心。

除此以外，人民币跨境使用基础设施建设，国际创新能力和创新手段，人民币国际定价、 交易、结算功能等影响人民币国际化的各种问题, 都尚处于起步阶段。新时代应该有新的途 径和渠道去推动这些问题的解决，通过 “一带一路” 战略、亚洲基础设施投资银行、人民币 原油期货市场以及其他新时代蓝图规划，形成人民币国际化的全新战略路径。

\section{4. 人民币国际化的目标选择与战略路径}

\section{1 新时代人民币国际化的目标选择}

中国新时代是开放引领的新时代，其核心意涵之一是持续扩大开放，并在更高层次和更 多领域实现开放。但开放不是最终目的, 最终目的是建成社会主义现代化强国。实现这一伟 大目标, 在对外经济领域就必须要 “主动参与和推动经济全球化进程, 发展更高层次的开放 型经济”。从这一角度来看, 推动金融领域双向开放, 实现人民币国际化, 是站在新时代的历 史方位为实现国家建设和民族复兴所作出的必然选择。因此, 不断扩大金融双向开放的领域, 深化开放程度，持续推动人民币国际化，必须围绕金融工作服务实体经济和不发生系统性金 融风险两个基本原则，而不能舍本逐末，将人民币国际化作为最终目标。 
实现经济稳定增长和为中国参与世界经济服务是人民币国际化的目标，作为实现目标的 手段, 人民币国际化首先要确保通过国家战略为对外活动中的中国经济主体提供足够的风险 屏障, 降低对外交易的成本和面临的汇率波动风险, 并提供可以锁定风险或对冲风险的工具, 从而实现为实体经济服务的金融目标。其次，在扩大开放的同时确保不因金融开放导致系统 性的金融风险, 这需要利用人民币的国际化进程加快国内金融市场与国际金融体系的融合, 形成内外适用的金融话语体系，并提升中国在国际金融市场的话语权，增强风险防范能力。 最后, 与中国的经济体量和对全球经济增长的贡献相匹配, 人民币国际化必须要发挥中国作 为世界经济核心舞台的成员所体现的全球治理能力, 特别是在经济领域提供来自中国的新兴 市场力量，建设稳健、有序、公平、可持续的国际货币体系新秩序，为全球经济稳定增长保 驾护航，引领全世界人类命运共同体向前发展。

\section{2 新时代人民币国际化的战略路径}

\subsection{1 探索人民币由证券和储备资产双驱动的发展方向，参与全球金融治理}

人民币国际市场的发育与成熟，可以提高其资产规模和便利性，也可以通过流动程度的 提高稳定人民币币值, 促进经济的稳定增长, 进而巩固其国际货币属性, 在承担国际金融市 场投融资功能的同时，强化其储备货币的地位。在国际化初始阶段，较低水平的金融开放程 度和人民币国际交易规模限制了境外主体对于人民币资产的配置状况。随着人民币资本账户 可兑换的稳步推进和人民币国际地位的提升，特别是随着 2016 年纳入 SDR 货币篮子，各国央 行、主权基金等官方货币机构以及市场化金融机构均开始主动管理人民币标的资产。只有探 索由市场投融资工具和储备资产双重驱动的发展方向，人民币才能实现真正的国际化目标。

境外官方外汇储备中人民币资产规模和比例的增加，以及国际货币基金组织开始在官方 储备中单独列示人民币资产等，对市场投资机构持有人民币计价资产具有积极作用。在此背 景下，应积极推动评级机构对人民币债券的评级工作支持，进一步提高中国金融数据的透明 度，从而加大国际市场对人民币金融资产的接受程度。继续优化合格境外机构投资者和人民 币合格境外投资者的管理机制，利用好债券通等境外市场融资平台，在扩大人民币国际资金 融通市场规模的同时，将先进的债券发行管理技术引入境内债券市场，提高债券市场对外开 放水平。同时积极推动熊猫债发行主体多元化，优化熊猫债账户开立、资金存管、跨境汇划 和数据报送的规则, 构建关于熊猫债的数据统计监测和宏观审慎管理体系, 引导境外金融机 构、非金融企业、国际开发金融机构等在我国境内发行人民币债券。推动以 SDR 计价, 人民 币发行的木兰债券发行，在国际市场扩大 SDR 使用范围，并以此推动人民币的国际交易。人 民币国际化的深化, 不能一条腿走路, 必须保证由证券和储备资产双重牵引, 同时, 证券资 产和储备资产也互为支持，相互促进，从而能够更好地为人民币国际化服务。

\subsection{2 完善稳健有序的金融市场建设, 提升离岸和在岸双市场的金融支撑体系}

作为人民币国际化的三大基础，我国经济总量和国际贸易基础显然早已夯实，当前需要 进一步完善稳健有序的金融市场, 并利用好人民币离岸市场和境内货币市场。目前, 离岸人 民币市场已经成为境外金融机构进行投融资的场所之一，离岸市场引领着人民币国际化和我 国金融开放的道路。但真正实现人民币国际化，推动人民币逐渐成为国际储备货币，发挥国 际货币职能, 需要金融领域的双向开放, 需要离岸金融市场和国内金融市场的双重支撑。只 有不断在境内市场为国际投资者提供更多更大规模的合规资金安排，更加合理便利的资金融 通渠道和流动性管理，才能吸引境外机构持续利用人民币作为结算交易和风险管理工具，从 而推动人民币国际化。

在境内金融市场建设方面，首先是在风险防范的基础上建立与国际金融市场通行的话语 体系和交易规则，使国内金融市场与国际市场接轨。随着金融市场开放领域的持续扩大和开 放程度的不断加深, 不同的市场范式导致的交易成本和流动性障碍将逐渐增加, 从而阻碍资 
本在境内外市场的双向流动，不利于人民币国际化进程。其次，稳步有序推进人民币资本项 目可兑换，强化国际市场对人民币的信心。资本项目尚不能完全可兄换是境外资本对人民币 信心不足的重要原因，尽管部分项目的资本管制是当前风险防范的要求，但随着双向开放进 程的推进，应积极寻求此类风险的对冲政策，而非抱守残缺限制条件成熟项目下的资本自由 进出便利。在人民币利率市场化改革逐渐完成之后, 强化对市场基准利率和收益率曲线的培 育，健全市场化利率形成机制和自律定价机制，并逐步完善利率走廊建设。利用自由贸易区 积极开展金融开放和改革试点, 总结经验并将相关有效机制积极向全国推广，逐步实现在岸 与离岸金融市场的有序发展和积极互动，在保持人民币币值稳定的同时形成境内外金融市场 对人民币国际化的双重支撑。

\subsection{3 利用 “一带一路”建设加强金融创新，推进人民币国际化进程}

“一带一路” 战略和人民币国际化均是我国在新时代向世界贡献的全球公共物品，两者 共同对中国新时代对外开放新格局的构建起到重要的引领作用，同时也必然产生巨大的协同 效应，从而相互促进，互相成就。从“一带一路” 战略和人民币国际化的内在逻辑来讲，“一 带一路” 战略的实施和发展为人民币国际化提供了广阔空间, 并且是检验人民币能否承担国 际货币职能的重要标准，而人民币国际化则为 “一带一路” 战略提供了必要的金融基础设施 和工具, 并在此过程中降低 “一带一路” 战略的实施风险。这种内在逻辑必将使两者在推进 过程中不断互动, 最终发挥出彼此的最大化效用。“一带一路” 战略过程中以基础设置建设、 能源开发利用为代表的经济活动, 需要大量的金融创新支持, 这是人民币国际化重要的动力 之源。同时，作为我国主导的重大国际交往战略，“一带一路” 建设必将始终与我国的经济结 构、贸易规模、金融体系发育程度紧密相关，其实现过程是必将与我国实际情况相适应，提 高人民币国际化中必要的容错空间。

在 “一带一路”建设中推进人民币国际化进程，一是在“一带一路”沿线国家加大人民 币跨境使用基础设施建设，积极促进相关国家使用并储备人民币资产。“一带一路”建设中的 资金来源主要是我国主导的政策性贷款、开发性贷款、国际债券和援助资金等，这种资金筹 集方式使得人民币在沿线国家的使用得到推广。二是利用开发性金融机构和中资金融机构的 投融资机制，提高人民币在沿线国家的流动性。以亚投行为代表的开发性金融机构和大型中 资金融机构，可以利用人民币在结算领域的集聚效应和对其他国家货币的替代效应，推动人 民币在全球资产配置、定价过程中的作用发挥，提高人民币全球化向更高水平迈进。三是构 建并完善人民币计价、交易、结算的大宗商品市场，提高人民币在资产定价方面的地位。“一 带一路” 建设设计大量的能源、原材料和农产品交易，推动以人民币为中心的大宗商品定价 机制, 有助于我国企业在相关经济活动中的风险防范, 同时可以打破美元全球资产定价体系, 掌握资产定价话语权，从而实现人民币国际化为实体经济服务的目的。四是在沿线国家扩大 并丰富人民币债券发行，为人民币国际债券发行扩大市场。“一带一路” 建设需要巨量的项目 融资，中国主导的融资体系应抓住机遇为市场提供合规、适用的人民币债券资产。

\section{References}

[1] Aaron T, Frank W, Lorenza M. The Positive Link between Financial Liberalization, Growth and Crises[J]. Ucla Economics Working Papers, 2010 (3).

[2] Kawai M. , Pontines V.. Is There Really A Renminbi Bloc in Asia: A Modified Frankel-Wei Approach $[\mathrm{J}]$. Journal of International Moneyand Finance, 2016 (62) : 72-97.

[3] Wang, Gang Jin, Chi Xie. Tail Dependence Structure of the Foreign Exchange Market: A Network View. Expert Systems with Applications, 2016 (46) : 164-179.

[4] Tropeano, Domenica. Financial Fragility in The Current European Crisis[J]. Social Science Electronic Publishing, 2013 (9). 
[5] Edwin L. -C. Lai and Xiangrong Yu, "Invoicing Currency in International Trade: An Empirical Investigation and Some Implications for Renminbi, ” The World Economy, Vol. 38, No. 1, 2015, pp. 193-229.

[6] HUA Dongling. The Influence of China's Two-way Financial Openness on Financial Fragility and Prevention of the Fragility [J]. Journal of Tianjin Normal University (Social Science), 2016 (3): 76-80. 